\title{
A problemática dos resíduos sólidos e ações de conservação na praia de Búzios, Rio Grande do Norte: um estudo sobre a percepção ambiental da comunidade local e frequentadores
}

\footnotetext{
Considerando a relevância das zonas costeiras para atividades humanas e a necessidade de conservação desses espaços, diversos trabalhos têm sido desenvolvidos buscando compreender a Percepção Ambiental (PA) dos frequentadores sobre a relação do homem com o ambiente marinho e a relevância da sua conservação. Desta forma, sabendo que as praias se constituem espaços de lazr, estes se tornam ambientes bastante impactados em virtude da presença humana e consumo na região, é importante analisar como o homem vê esse ambiente e como interfere nele, para que assim, possam ser apresentadas medidas que minimizem esses impactos. Nesta perspectiva, o presente trabalho teve como objetivo investigar a Percepção de frequentadores da praia de Búzios, Nísia floresta, RN, acerca da problemática dos resíduos sólidos, bem como, traçar um perfil dos banhistas, e, realizar um levantamento de ações de conservação. A presente pesquisa apresenta uma abordagem quali-quantitativa e exploratória, com procedimentos direcionados a levantamento de dados e análise de conteúdo. Os conservação. A presente pesquisa apresenta uma abordagem quali-quantitativa e exploratória, com procedimentos direcionados a levantamento de dados e análise de conteúdo. Os
resultados obtidos a partir das entrevistas possibilitou identificar tendências diversas sobre a percepção dos frequentadores a respeito da praia de Búzios e seu ambiente físico. A pesquisa possibilitou discutir a relação do homem com a natureza a partir da perspectiva do próprio homem. Dessa forma, evidencia-se a necessidade de estudos que possibilitem a implementação de politicas públicas que subsidiem uma melhor orientação e fiscalizaçăo nas praias urbanas.
}

\section{The issue of solid waste and conservation actions on the beach in Búzios, Rio Grande do Norte: a study on the environmental perception of the local community and patrons}

Considering the relevance of coastal areas for human activities and the need to conserve these spaces, several works have been developed seeking to understand the Environmental Perception (AP) of the regulars about the relationship between man and the marine environment and the relevance of its conservation. In this way, knowing that the beaches are leisure spaces, they become very impacted environments due to the human presence and consumption in the region, it is important to analyze how man sees this environment and how it interferes in it, so that they can be measures are presented to minimize these impacts. In this perspective, this study aimed to investigate the perception of beachgoers in Búzios, Nísia Floresta, RN, about the problem of solid waste, as well as to outline a profile of bathers, and conduct a survey of conservation actions. This research presents a qualitative and quantitative and exploratory approach, with procedures aimed at data collection and content analysis. The results obtained from the interviews made it possible to identify different trends in the perception of regulars regarding Búzios beach and its physical environment. The research made it possible to discuss the relationship between man and nature from the perspective of man himself. Thus, there is a need for studies that enable the implementation of public policies that support better guidance and inspection on urban beaches.

Keywords: Environmental perception, Environmental Education, Solid waste

Topic: Uso de Recursos Naturais

Reviewed anonymously in the process of blind peer.

Simony Souza Santos (iD

Centro Universitário UNIFACEX, Brasi

http://lattes.cnpq.br/0241309001691077

http://orcid.org/0000-0002-9064-7320

sss mony@gmail.com

Clécio Danilo Dias da Silva

Universidade Federal do Rio grande do Norte, Brasil

http://lattes.cnpq.br/4235157508528733

http://orcid.org/0000-0002-7776-8830

danilodiass18@ufrn.edu.br

Lúcia Maria de Almeida

Centro Universitário UNFACEX, Brasil

http://lattes.cnpq.br/6281405605667040

http://orcid.org/0000-0001-6435-0892

Imalmeida@gmail.com
Received: 06/04/2021

Approved: 05/05/2021
Priscila Daniele Fernandes Bezerra Souza

Centro Universitário UNFACEX, Brasil

http://lattes.cnpq.br/7804691550281956

http://orcid.org/0000-0002-2474-9193

prisciladaniele@yahoo.com.br
Referencing this:

SANTOS, S. S.; SILVA, C. D. D; ALMEIDA, L. M.; SOUZA, P. D. F. B.. A problemática dos resíduos sólidos e ações de conservação na praia de Búzios, Rio Grande do Norte: um estudo sobre a percepção ambiental da comunidade local e frequentadores. Natural Resources, v.11, n.2 p.117-126, 2021. DOI: http://doi.org/10.6008/CBPC22379290.2021.002.0012 


\section{INTRODUÇÃO}

Conforme Guimarães et al. (2017) um dos lugares mais usufruídos pelo homem como espaço de lazer são as praias localizadas em áreas litorâneas devido a fatores climáticos característicos que estes lugares possuem tais como: sol, vento, mar e contato com a natureza. Filho et al. (2010) afirma que o brasileiro é um frequentador assíduo de praias, visto que, o baixo custo desse tipo de lazer e o clima ameno favorecem essa prática, principalmente em períodos de alta estação. No entanto, ao mesmo tempo em que as praias são consideradas ambientes comuns de recreação a sociedade, esses lugares vêm sofrendo pressões ocasionadas, principalmente, pela falta de educação e consciência das pessoas que circulam nesses espaços.

No Brasil a média de lixo gerado diariamente aumentou de 0,5 para 1,2 kg ao dia por indivíduo, este modo de vida moderno torna-se um dos maiores responsáveis por tal degradação ambiental dos oceanos e a redução de diversidade biológica do mundo (SILVA et al., 2012; FERNANDES et al., 2013). O lixo presente nas praias é o resultado de uma falta de política pública válida em relação ao descarte dos resíduos sólidos, muitas vezes estes resíduos são lançados ao mar como forma de livrar-se temporariamente de tal problema, eliminando de forma desrespeitosa e irresponsável, poluindo suas águas e atingindo diretamente na saúde e na economia do homem (ARAÚJO et al., 2003).

Os oceanos são fontes de riquezas indescritíveis, responsáveis pelos maiores produtores de oxigênio do mundo: as algas marinhas, a partir da presença do mar, outros ecossistemas (estuários, praias, manguezais, restingas, etc.) interdependentes precisam da sua conservação, sendo também importantes para as atividades econômicas (MORAES, 2007).

Dentro deste contexto, considerando a relevância das zonas costeiras para atividades humanas e a necessidade de conservação desses espaços, diversos trabalhos têm sido desenvolvidos buscando compreender a Percepção Ambiental (PA) dos banhistas e frequentadores sobre a relação do homem com o ambiente marinho e a relevância da sua conservação (FILHO et al., 2010; SILVA et al., 2016; GUIMARÃES et al., 2017). Conforme Fernandes (2003) a PA pode ser definida como sendo uma tomada de consciência do ambiente pelo homem, ou seja, o ato de perceber o ambiente que se está inserido, aprendendo a proteger e a cuidar do mesmo. De acordo com este autor, cada indivíduo percebe, reage e responde diferentemente às ações sobre o ambiente em que vive. As respostas ou manifestações daí decorrentes são resultado das percepções (individuais e coletivas), dos processos cognitivos, julgamentos e expectativas de cada pessoa (FERNANDES, et al., 2003).

Ressalta-se que esses estudos de PA vêm obtendo uma grande relevância como forma de compreender, observar e vivenciar a realidade dos frequentadores de determinada região. Desta forma, sabendo que as praias se constituem espaços de lazer, estes se tornam ambientes bastante impactados em virtude da presença humana e o consumo na região, importa analisar como o homem vê esse ambiente e como interfere nele, para que assim, possam ser apresentadas medidas que minimizem esses impactos. Nesta perspectiva, o presente trabalho teve como objetivo investigar a Percepção de frequentadores 
A problemática dos resíduos sólidos e ações de conservação na praia de Búzios, Rio Grande do Norte: um estudo sobre a percepção ambiental da

acerca da problemática dos resíduos sólidos na praia de Búzios, Nísia floresta, RN, bem como, traçar o perfil dos banhistas, e, realizar um levantamento de conservação.

\title{
REVISÃO TEÓRICA
}

Órgãos públicos responsáveis pela coleta de lixo urbana, esporadicamente buscam amenizar a realidade do lixo nas praias, porém não é uma medida que reduz o impacto causado ao ambiente em longo prazo. Não obstante, através dessas medidas não é possível a coleta total dos pequenos fragmentos dos resíduos sólidos, resíduos estes que são constantes com o vai e vem da maré (SANTOS et al., 2004). Estes vestígios expõem em um alto grau de risco toda a biota marinha, além das aves e os seres humanos que também são afetados, prejudicando toda a economia local com a redução de frequentadores e impactando diretamente no comércio regional (DIAS FILHO, 2011).

Nessa perspectiva, ressalta-se o debate em torno da relação homem-natureza e os impactos do consumismo exacerbado, evidenciando a necessidade em reduzir o consumo para que como consequência reduza-se também a produção de resíduos sólidos (RS), o que não vem ocorrendo, pelo contrário, essa produção vem se elevando (FERREIRA, 2003). Assim, Godoy (2007) afirma que a Educação Ambiental nas escolas tem papel essencial para a conservação do meio ambiente, visando conscientizar as novas gerações dos impactos causados e suas futuras consequências, cientes das responsabilidades individuais e pensando no coletivo, tornando-os responsáveis pelas gerações futuras.

\begin{abstract}
Educar para o meio ambiente apresenta-se como o cumprimento de prescrições que reduzem os corpos e as relações à conservação. Tais prescrições pautam-se no que se deve ou não fazer, no que se pode ou não fazer segundo um modelo de perfeição e pureza permanentemente inalcançável, pois frente à natureza a ser conservada nunca se faz o bastante, nunca se é bom o bastante, nunca se sabe o bastante e todo cuidado permanece sendo pouco. (GODOY, 2007)
\end{abstract}

Segundo Freire (1993), a Educação Ambiental precisa ser constante de acordo com a evolução natural das espécies, adaptando-se ao modo de vida da população de acordo com as gerações. Impactando o mínimo possível o meio ambiente e englobando as necessidades das gerações, suprindo a necessidade de ambos.

A educação ambiental, devidamente entendida, deveria constituir uma educação permanente, geral, que reage às mudanças que se produzem em um mundo em rápida evolução. Essa educação deveria preparar o indivíduo, mediante a compreensão dos principais problemas ambientais do mundo contemporâneo, proporcionando-lhe conhecimentos técnicos, qualidades necessárias para desempenhar uma função produtiva, com vistas a melhorar a vida e proteger o meio ambiente, prestando a devida atenção aos valores éticos. (FREIRE, 1993)

Convey et al. (2002) afirma que o lixo marinho está presente nos litorais costeiros brasileiros tanto quanto em regiões circunvizinhas a centros urbanos como em regiões inabitadas, assim, comprovando que o lixo marinho não é apenas o que é perceptível a olho nu quando por exemplo caminhamos na praia e visualizamos apenas embalagens plásticas. Espaços costeiros são os mais impactados devido as ações antrópicas em áreas continentais, praias metropolitanas são as mais vulneráveis a poluição, sendo as mais afetadas diretamente atrapalhando o desenvolvimento social e ambiental da região (SILVA et al., 2009). 
A problemática dos resíduos sólidos e ações de conservação na praia de Búzios, Rio Grande do Norte: um estudo sobre a percepção ambiental da

Segundo Goldberg (1995), o excessivo e desenfreado crescimento populacional em áreas de zonas costeiras é a causa principal e determinante para o acréscimo da poluição nas zonas costeiras, havendo proporcionalmente um maior consumo e geração de resíduos sólidos nestas regiões naturais. Indicando agravantes como: longo tempo de moradia, ampliação e intensificação de moradores ao decorrer dos anos, área com grande disponibilidade de dispersão de moradores; inserindo ainda mais quantidade de lixo doméstico aos resíduos sólidos encontrados em regiões costeiras, tornando os resíduos sólidos um dentre os maiores poluidores marinhos. Para Cheshire et al., (2009), dentre inúmeros impactos ambientais ocasionado por resíduos sólidos temos a pesca fantasma, a ingestão destes resíduos fragmentados, sufocamento de recifes, banco de algas e manguezais; ocorrendo também impactos sociais com a perda da estética da praia, ocasionando risco a saúde e segurança dos frequentadores; impactando economicamente com a redução turística e danos causados as embarcações.

A pesca fantasma vem ganhando espaço nos últimos tempos, devido ao seu crescente impacto na fauna marinha (GILMAN, 2015; SULLIVAN, 2019). Resíduo sólido nem sempre visualizado aos olhos nus dos frequentadores das praias em dias de domingo, originados da perda ou descarte ilegal de material de pesca que continuam a capturar animais e outros organismos por um longo período, compostos de materiais de grande durabilidade a sua decomposição pode durar dezenas de anos (ALVES et al., 2016). Anualmente materiais pesqueiros podem chegar até 640 mil toneladas deixados no mar (WORLD ANIMAL PROTECTION, 2018).

Em várias regiões do Brasil se tem sido divulgado a presença de resíduos sólidos nas praias costeiras como Maranhão, por Silva et al. (2003), na Bahia por Sul (2005), no Rio de Janeiro por OigmanPszczol e Creed (2007) e no Rio Grande do Sul por Carvalho (1999). Santos et al. (2008) criaram um capítulo de um livro com um pequeno resumo da problemática dos resíduos sólidos: flutuantes, depositados no fundo do mar e as consequências quando ingeridos pelos animais. Tudo voltado para o público leigo.

A existência dos resíduos no litoral brasileiro é ocasionada por diversos motivos, entre eles o maior responsável é ausência de consciência ambiental da sociedade e sua classe social que também influencia no nível educacional, assim não cumprindo o seu dever de cidadão e responsabilizando o Estado (ARAÚJO, 2003). Estima-se através de estudos que o lixo marinho está distribuído mundialmente em: $15 \%$ no litoral terrestre, outros $15 \%$ na superfície dos mares e os outros $70 \%$ estão no fundo do mar distante dos olhos humanos, podendo ser esses últimos dados muito maiores (CORREIA, 2016). Tais dados causam danos irreversíveis à biota marinha, outrora a questão de acúmulo de resíduos beira mar era apenas considerado esteticamente feio, porém atualmente sabe-se que os resíduos vão bem mais além de uma questão estética, os resíduos além de trazerem prejuízos a fauna trazem também danos econômicos a região. (ARAÚJO et al., 2003).

Para tanto, em meio a essa discussão, a Percepção Ambiental (PA) surge como uma ferramenta para avaliar a postura dos indivíduos frente a problemáticas relacionadas ao meio ambiente. Assim, podese dizer que a percepção é a função cerebral que atribui significados a estímulos sensoriais, um processo cognitivo de absorção de um conhecimento ou alguma coisa presente no meio. Este processo ocorre 
A problemática dos resíduos sólidos e ações de conservação na praia de Búzios, Rio Grande do Norte: um estudo sobre a percepção ambiental da

involuntariamente, assim beneficiando a compreensão e conscientização. A percepção ambiental da sociedade depende de como os problemas ambientais lhes são expostos, assim a atuação dos mesmos de forma participativa contribui de forma benéfica para o ambiente e para toda a comunidade, resultando em uma quebra de corrente de suceder a informação que apenas a gestão pública é responsável por medidas socioambientais. Transformando, assim um novo padrão de sociedade, mais conscientes, mais desenvolvidos e mais proativos (HAMMES, 2012). Segundo Fernandes (2004) a PA tem o propósito de identificar antecipadamente dados de um assunto específico constatando problemas e a partir destes dados, estudar e tomar medidas mitigadoras para amenizar ou solucionar o problema. A percepção ambiental é de grande importância para a criação de programas educativos para a sociedade, iniciando-se na fase escolar e estendendo-se até a comunidade.

Existe um grande interesse e prontidão de estudantes do nível superior das faculdades públicas e privadas na realização de estudos de percepção ambiental na biologia marinha, porém lamentavelmente no Brasil não existe incentivo e a maioria deles não chegam nem se quer a serem publicados (VASCONCELOS, 2008). É indiscutível e necessário a inserção da Educação Ambiental (EA) em longo prazo e permanentemente, tento como conteúdos resíduos sólidos no ambiente marinho. Mas para um reconhecimento minucioso é indispensável um diagnóstico realizado através da percepção ambiental com os envolvidos na problemática (REIGOTA, 2002; PEDRINI et al. 2010).

\section{METODOLOGIA}

A presente pesquisa apresenta uma abordagem quali-quantitativa e exploratória, com procedimentos direcionados a levantamento de dados e análise de conteúdo. De acordo com Souza e Kerbauy (2017) a pesquisa quali-quantitativa, maiormente conhecida como pesquisa mista, consiste na integração de elementos da abordagem qualitativa e quantitativa, o que possibilita aos pesquisadores entenderem e compreenderem de uma maneira holística os problemas complexos enfrentados pela sociedade (SOUZA et al., 2017). Flick (2009) afirma que a convergência dos métodos quantitativos e qualitativos proporcionam mais credibilidade e legitimidade aos resultados encontrados, evitando o reducionismo à apenas uma opção. No que diz respeito a pesquisa descritiva, Flick (2009) afirma que ela objetiva descrever as características de determinada população ou fenômeno ou o estabelecimento de relações entre variáveis diversas. Ela visa ainda descobrir a frequência com que um fato ocorre, sua natureza, suas características, causas, relações com outros fatos (PRODANOV et al., 2013). Ainda conforme os autores, neste tipo de pesquisa ocorre a observação, registro, análise e ordenamento dos dados sem manipulação/interferência do pesquisador.

O desenvolvimento da pesquisa se deu no mês de setembro por meio de entrevistas com 105 frequentadores da praia de Búzios, município de Nísia Floresta, Rio Grande do Norte. Considerando amplitude da praia investigada, delimitou-se um transecto de aproximadamente $03 \mathrm{~km}$, o qual abarcou o início da praia até a região mais central e de maior número de banhistas e barracas a beira mar (Figura 1). A área onde o estudo foi realizado faz parte da APA Bonfim-Guaraíra (ABG), a APA Bonfim-Guaraíra (ABG) é 
localizada no litoral oriental do estado e possui 43 mil há, criada em 02 de abril de 1998 pelo decreto no 7.272; área com grande diversidade de vegetais e animais relacionados a Mata Atlântica, possuindo um grande valor ambiental. As entrevistas foram efetivadas utilizando-se de um roteiro com 07 questionamentos previamente definidos sobre a problemática dos resíduos sólidos.

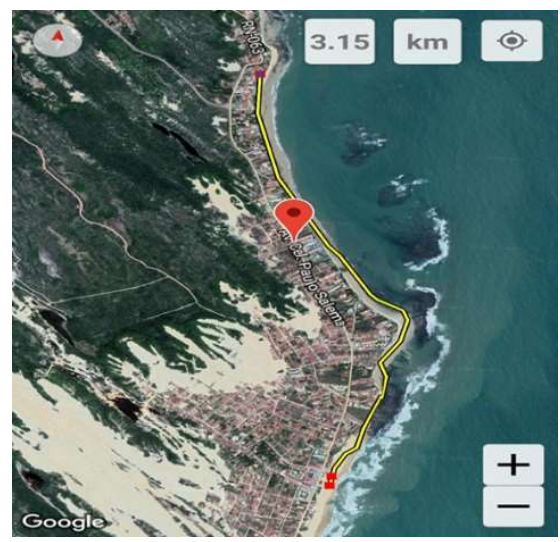

Figura 1: Transecto percorrido para realização das entrevistas. Fonte: Google Maps (2021).

Os registros das entrevistas passaram por um processo de leituras exploratórias, categorização e avaliação utilizando-se de aspectos da análise de conteúdo de Bardin (2011). Esse processo de categorização consiste na classificação de elementos constitutivos de um conjunto, por diferenciação e por agrupamento segundo os critérios previamente definidos, efetuado em razão dos caracteres comuns destes elementos (BARDIN, 2011). Para finalizar, os dados categorizados foram tabulados em planilhas do Microsoft Office Excel 2010 para elaboração de gráficos e tabelas.

\section{RESULTADOS E DISCUSSÃO}

Os resultados obtidos a partir das entrevistas possibilitou identificar tendências diversas sobre a percepção dos frequentadores a respeito da praia de Búzios e seu ambiente físico. A amostra foi constituída por 105 investigados, destes 59\% eram do sexo feminino, e $41 \%$ eram do sexo masculino (Figura 2).

Verificou-se que dos investigados, 33\% residiam próximos à praia, e $67 \%$ eram apenas frequentadores. Esses dados são relevantes, pois evidenciam que as pessoas que estavam na praia de Búzios não eram moradores da localidade, e, provavelmente, residiam em localidades mais afastadas da praia investigada. Esse fato pode estar associado ao período das entrevistas, que ocorreu durante um prolongado feriado no mês de setembro. $\mathrm{O}$ aumento de frequentadores nas praias foi relatado por Filho et al. (2010), que observaram que o aumento de banhistas de outros bairros, municípios, estados são mais comuns em períodos de férias e/ou feriados (FILHO et al., 2010; FERNANDES et al., 2013).

Com relação a faixa etária dos entrevistados, percebeu-se que a predominância dos banhistas foi de indivíduos entre 20 à 30 anos (28\%), seguidos das faixas de 30 à 40 anos (25\%), 40 a 50 anos (20\%), mais de 60 anos (16\%) e, 50 a 60 anos (11\%). 


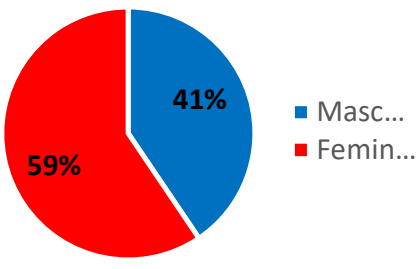

Figura 2: Sexo dos participantes da pesquisa.

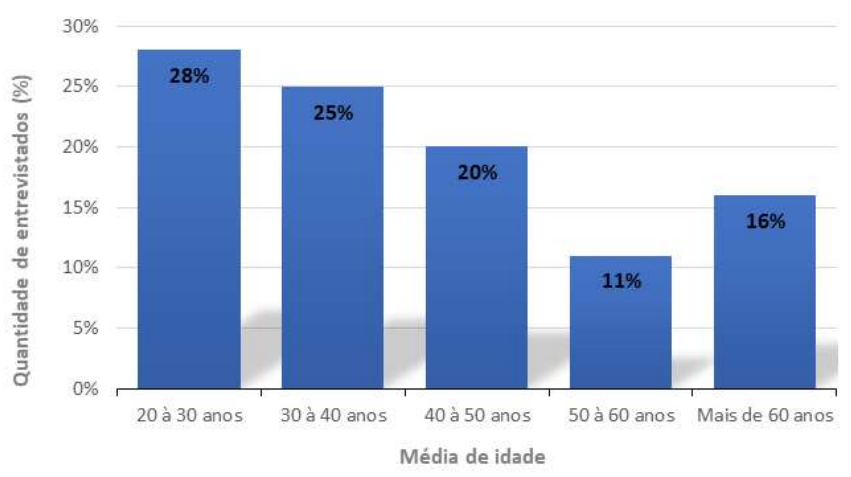

Figura 3: Faixa etária dos banhistas entrevistados.

No que diz respeito ao nível de escolaridade, a predominância foi para aqueles que apresentavam ensino médio completo (46\%), seguido do ensino superior (40\%) e ensino fundamental (14\%) (Figura 4).

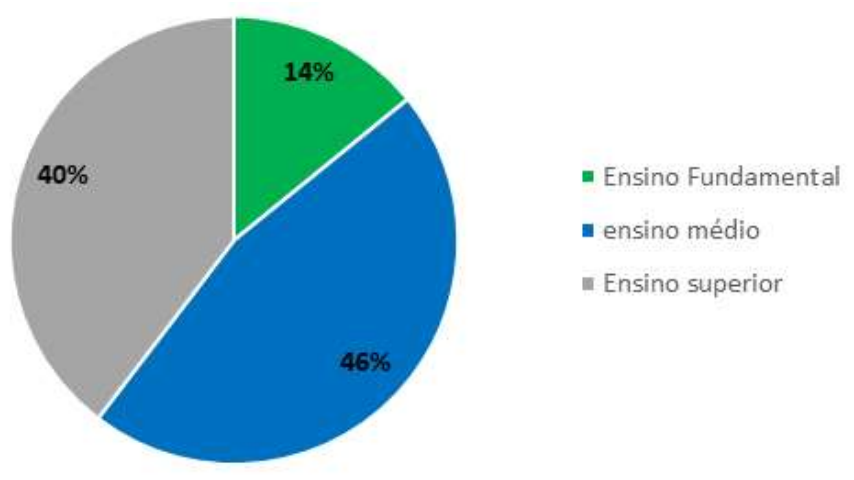

Figura 4: Nível de escolaridade dos banhistas entrevistados.

Durante as entrevistas, duas imagens foram apresentadas aos entrevistados (Quadro 1), a primeira representando o ambiente físico da praia limpo, e a segunda com esse ambiente poluído. Ao exibir as imagens eram questionados aos banhistas o que vinha a sua mente ao visualizá-las. As respostas foram divididas em 07 categorias, as quais podem ser visualizadas no Quadro 2.

Quadro 1: Perspectiva dos turistas concernentes à praia limpa e praia poluída.

\begin{tabular}{|c|c|c|c|}
\hline Categorias & Descrição & $\begin{array}{l}\text { Frequência } \\
\text { Praia limpa }\end{array}$ & $\begin{array}{l}\text { Frequência praia } \\
\text { poluída }\end{array}$ \\
\hline Aspectos sentimentais & $\begin{array}{l}\text { Respostas com elementos ligados a emoções positivas e } \\
\text { negativas diversas. } \\
\text { Ex.: Divino; Triste. }\end{array}$ & $55 \%$ & $45 \%$ \\
\hline $\begin{array}{l}\text { Aspectos políticos e } \\
\text { legislativos }\end{array}$ & $\begin{array}{l}\text { Respostas com elementos ligados à partidos políticos, figuras } \\
\text { políticas, citando nomes dos atuais gestores. }\end{array}$ & - & $13 \%$ \\
\hline Aspectos estéticos & $\begin{array}{l}\text { Respostas com elementos ligados ao estado estético } \\
\text { harmonioso da praia. }\end{array}$ & $19 \%$ & $12 \%$ \\
\hline Aspectos sazonais/temporal & $\begin{array}{l}\text { As respostas apresentavam elementos ligados a relação } \\
\text { estabelecida entre as estações do ano/temporada de férias ao } \\
\text { estado físico da praia. }\end{array}$ & $6 \%$ & $2 \%$ \\
\hline Aspectos de lazer e cultura & $\begin{array}{l}\text { As respostas apresentavam elementos ligados a práticas } \\
\text { esportivas, descanso, socialização, recreação e entretenimento. }\end{array}$ & $6 \%$ & \\
\hline $\begin{array}{l}\text { Aspectos relacionados à } \\
\text { ação antrópica }\end{array}$ & $\begin{array}{l}\text { As respostas apresentavam elementos ligados aos impactos } \\
\text { ambientais e sanitários ocasionados pela ação humana. }\end{array}$ & & $23 \%$ \\
\hline Outros & $\begin{array}{l}\text { As respostas não apresentavam elementos que as } \\
\text { enquadrassem nas categorias anteriores. }\end{array}$ & $13 \%$ & $5 \%$ \\
\hline \multicolumn{2}{|l|}{ Frequência total: } & $100 \%$ & $100 \%$ \\
\hline
\end{tabular}

Como pode ser visualizado no Quadro 1, as respostas dos banhistas com relação à praia limpa 
estavam maiormente relacionadas à "aspectos sentimentais" com 55\% ("Sinto felicidade", "tenho paz", "fico alegre", etc.), e "aspectos estéticos" com 19\% ("Praia belíssima", "lugar lindo", "lugar maravilhoso", etc.). No tocante às respostas relacionadas à praia poluída, predominou-se aquelas inclusas em "aspectos sentimentais" com 45\% ("Uma tristeza", "fico angustiado", "desapontado", etc.), e "aspectos relacionados à ação antrópica" ("o ser humano polui tudo", "é culpa do homem", etc.).

Quando os banhistas foram indagados se visualizavam algum problema ambiental na praia de Búzios, $67 \%$ asseguraram que sim, 33\% afirmaram que não. As problemáticas visualizadas pelos entrevistados podem ser visualizadas na Figura 5.

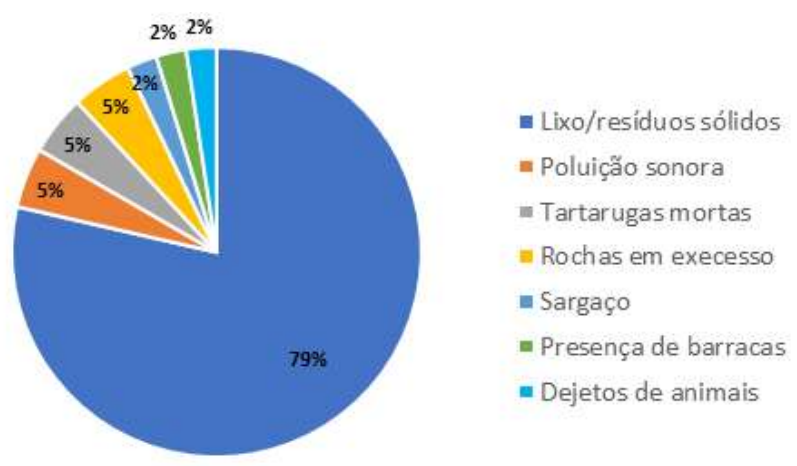

Figura 5: Principais problemas descritos pelos entrevistados.

Como pode ser observada na Figura 5, a maioria dos entrevistados apontam a presença de lixo/resíduos sólidos como a maior problemática da praia de Búzios, sendo citada a presença de "bitucas" de cigarro, fraldas, latas de refrigerante, garrafas, dentre outros. Conforme Araújo e Costa (2003) o lixo marinho, se constitui como uma das problemáticas mais evidentes na atualidade. Conforme os autores a presença de lixo na praia pode ocasionar diversos problemas socioambientais como: morte de animais marinhos e aves, propagação de vetores de doenças e contaminação dos frequentadores, transtornos estéticos aos banhistas, dentre outros. Torna-se relevante destacar que, diversos trabalhos na literatura apontam a presença de lixo/resíduos sólidos como uma problemática das praias em todo o Brasil como pode ser observado em Filho et al. (2010), Silva et al., (2012), Fernandes et al., (2013) Silva et al., (2016); Guimarães et al., (2017), dentre outros.

Após o apontamento das problemáticas visualizadas na praia de Búzios, solicitou-se aos entrevistados que citassem formas mitigadoras para sanar/minimizar as problemáticas percebidas. As sugestões dos entrevistados foram agrupadas em 05 categorias, como pode ser visto no Quadro 3.

Quadro 2: Ações mitigadoras apontadas pelos entrevistados para minimização dos problemas visualizados na praia de Búzios.

\begin{tabular}{|c|c|c|}
\hline Categorias & Descrição & Frequência \\
\hline $\begin{array}{l}\text { Ações de } \\
\text { Educação } \\
\text { ambiental }\end{array}$ & $\begin{array}{l}\text { As respostas apresentavam elementos relacionados conscientização e sensibilização dos } \\
\text { frequentadores quanto ao descarte dos resíduos sólidos, bem como, apontavam ações e práticas } \\
\text { de educação ambiental. }\end{array}$ & $42 \%$ \\
\hline $\begin{array}{l}\text { Redução de } \\
\text { vendas e } \\
\text { barracas }\end{array}$ & $\begin{array}{l}\text { As respostas apresentavam direcionamento à pratica de vendas de alimentos e bebidas na praia } \\
\text { (barracas, ambulantes, etc.). }\end{array}$ & $6 \%$ \\
\hline $\begin{array}{l}\text { Atuação } \\
\text { efetiva do } \\
\text { setor privado }\end{array}$ & $\begin{array}{l}\text { As respostas apresentavam apontamentos sobre a atuação de empresas privadas, ONGs/OSCs na } \\
\qquad \text { limpeza e conservação da praia. }\end{array}$ & $6 \%$ \\
\hline
\end{tabular}




\begin{tabular}{|c|c|c|}
\hline $\begin{array}{l}\text { Atuação } \\
\text { efetiva do } \\
\text { setor público }\end{array}$ & $\begin{array}{l}\text { As respostas apresentavam apontamentos sobre a atuação do governo e figuras políticas, bem } \\
\text { como apontavam práticas relacionadas à conservação da praia, bem como, traziam sugestões de } \\
\text { medidas a serem tomadas para com os frequentadores em caso de práticas que ocasionassem } \\
\text { dados ao ambiente da praia (prisão, multas, etc.) }\end{array}$ & $34 \%$ \\
\hline Outros & As respostas não apresentavam elementos que as enquadrassem nas categorias anteriores. & $12 \%$ \\
\hline \multicolumn{2}{|r|}{ Frequência total: } & $100 \%$ \\
\hline
\end{tabular}

Como mostra o Quadro 2 acima, os frequentadores apontaram diversas formas para minimizar as problemáticas isualizadas na praia de Búzios (Figura 6), destacando-se dentre elas as ações de educação ambiental (42\%) e a atuação efetiva do setor público (34\%). Estes resultados observados estão em conformidade com Marques et al. (2003), ao assegurar que: “o homem é o responsável pela degradação ambiental, porém pode vir dele mesmo a proposta para a conservação".

\section{CONCLUSÕES}

A pesquisa realizada possibilitou discutir a relação do homem com a natureza a partir da perspectiva do próprio homem. Verificou-se que os frequentadores da praia, independente da paisagem exposta (praia limpa ou suja), têm uma compreensão sentimental em relação ao ambiente. Além disso, nota-se ainda que os entrevistados acreditam que a educação ambiental exerce um importante papel na transformação da consciência humana, podendo mitigar os impactos provocados pela produção e disposição de resíduos na região em análise. Considera-se importante, portanto, a realização de estudos futuros que possibilitem uma aplicação efetiva de educação ambiental com os frequentadores, comerciantes e comunidade geral, a fim de possibilitar um gerenciamento eficiente do ambiente em questão. Importa ainda, que sejam implementadas políticas públicas que subsidiem uma melhor orientação e fiscalização nas praias urbanas.

\section{REFERÊNCIAS}

ALVES, J. A.. Abandoned, lost or otherwise discarded fishing gears in rocky reefs of Southern Brazil. Brazilian Journal of Oceanography, v.64, n.4, p.427-434, 2016.

ARAÚJO, M. C.; COSTA, M. F.. Lixo no ambiente Marinho. Ciência Hoje, v.32, n.191, p.64-69, 2003.

BARDIN, L.. Análise do conteúdo. São Paulo: Edições 70, 2011.

COUTINHO, J. C.. Conhecimento florístico atual e avaliação do uso do solo na APA Bonfim-Guaraíra, Rio Grande do Norte. Dissertação (Mestrado em Ciências Florestais) Universidade Federal do Rio Grande do Norte, Natal, 2020.

DIAS FILHO, M. J. O.. Contaminação da praia de Boa Viagem (Pernambuco-Brasil) por lixo marinho: relação com o uso da praia. Arquivos de Ciências do mar, v.44, n.1, p.33-39, 2011

FERNANDES, R. S.. Uso da Percepção Ambiental como instrumento de gestão em aplicações ligadas às áreas educacional, social e ambiental, 2020 .

FERNANDES, L. G.; SANSOLO, D. G.. Percepção ambiental dos moradores da cidade de São Vicente sobre os resíduos sólidos na Praia do Gonzaguinha, SP, Brasil. Revista de
Gestão Costeira Integrada, v.13, n.3, p.379-389, 2013.

FILHO, M. D.. Avaliação da percepção pública na contaminação por lixo marinho de acordo com o perfil do usuário: estudo de caso em uma praia urbana no Nordeste do Brasil. Revista de Gestão Costeira Integrada, v.11, n.1, p. 49-55, 2010.

FLICK, U.. Introdução à pesquisa qualitativa. Porto Alegre: Artemed, 2009.

FREIRE, P.. Política e educação. São Paulo: Cortez, 1993.

GOLDBERG, A. E.. Constructions: A construction grammar approach to argument structure. University of Chicago Press, 1995.

GUIMARÃES, L. F.; BRITO, F. S. L.. Descarte inadequado de resíduos sólidos na praia de Marudá-Marapanim-PA. In: CONGRESSO BRASILEIRO DE GESTÃO AMBIENTAL, 7. Anais. Campo GrandeConGeA, 2017.

HAMMES, V. S.. Como investigar o lixo. Embrapa Meio Ambiente, 2012.

MACHADO, R. C. A.. Percepção sócio-ambiental dos turistas 
A problemática dos resíduos sólidos e ações de conservação na praia de Búzios, Rio Grande do Norte: um estudo sobre a percepção ambiental da comunidade local e frequentadores

SANTOS, S. S.; SILVA, C. D. D; ALMEIDA, L. M.; SOUZA, P. D. F. B.

e trabalhadores da praia de Porto de Galinhas (PernambucoBrasil) acerca do ecossistema recifal. Revista de Gestão Costeira Integrada, v.9, n.3, p.71-78, 2009.

MARQUES, L. M.; CARNIELLO, M. A.. Educação ambiental nos quintais uma articulação entre escola e comunidade. Anais. EPEA: ABORDAGENS EPISTEMOLÓGICAS E METODOLÓGICAS, 2. São Carlos: Futura, 2003.

OIGMAN-PSZCZOL, S. S.; CREED, J. C.. Quantification and classification of marine litter on beaches along Armação dos Búzios. Journal of Coastal Research, v.23, n.2, p.421-428, 2007.

PEDRINI, A.; COSTA, E. A.; GHILARDI, N.. Percepção ambiental de crianças e pré-adolescentes em vulnerabilidade social para projetos de educação ambiental. Ciência \& Educação, v.16, n.1, p.163-179, 2010.

PRODANOV, C.; FREITAS, E. C. Metodologia do Trabalho Científico: métodos e Técnicas da Pesquisa e do Trabalho Acadêmico. 2 ed. Novo Hamburgo: FEEVALE, 2013.
REIGOTA, M.. El estado del arte de la educacioón ambiental en Brasil. Tópicos en Educación Ambiental, v.4, n.11, p.4962,2002

SILVA, M. E. M.; ANJOS, F. A.. Gestão da sustentabilidade em Meia Praia - Itapema (SC) sob a percepção dos visitantes e agentes locais. Revista Brasileira de Ecoturismo, v.5, n.2, p.223-244, 2012.

SILVA, V. C.. Contaminação por Enterococcus da água das praias do município de São Luís, Estado do Maranhão. Acta Sci. Technol, v.30, n.2, p.187-192, 2008.

SILVA, W. M.; TCHAICKA, L.; SÁ-SILVA, J. R.. Representações Sociais e Percepção Ambiental: a Balneabilidade de Praias de São Luís e São José de Ribamar, Revista Rosa dos Ventos, v.8, n.4, p.405-418, 2016.

SOUZA, K. R.; KERBAUY, M. T. M.. Abordagem quantiqualitativa: superação da dicotomia quantitativa-qualitativa na pesquisa em educação. Educação e Filosofia, v.31, n. 61, p.21-44, 2017.

A CBPC - Companhia Brasileira de Produção Científica (CNPJ: 11.221.422/0001-03) detém os direitos materiais desta publicação. Os direitos referem-se à publicação do trabalho em qualquer parte do mundo, incluindo os direitos às renovaç̃̃es, expansões e disseminações da contribuição, bem como outros direitos subsidiários. Todos os trabalhos publicados eletronicamente poderão posteriormente ser publicados em coletâneas impressas sob coordenação da Sustenere Publishing, da Companhia Brasileira de Produção Científica e seus parceiros autorizados. Os (as) autores (as) preservam os direitos autorais, mas não têm permissão para a publicação da contribuição em outro meio, impresso ou digital, em português ou em tradução. 